\title{
KEANEKARAGAMAN HAYATI VEGETASI PADA SISTEM AGROFOREST DI DESA SUNGAI SEKONYER, KABUPATEN KOTAWARINGIN BARAT, KALIMANTAN TENGAH
}

\author{
Vegetation Biodiversity in Agroforest System in Sungai Sekonyer Village, West Kotawaringin Regency,
} Central Kalimantan

\author{
Adisti Permatasari Putri Hartoyo $^{1}{ }^{*}$, Nurheni Wiyayanto ${ }^{1},{\text { Esperansa } \text { Olivita }^{1} \text {, Hanifa Rahmah }}^{1}$, \\ Amelia Nurlatifah ${ }^{1}$
}

(Diterima Juni 2019/Disetujui Agustus 2019)

\begin{abstract}
Sungai Sekonyer village is a village that bordered by Tanjung Puting National Park (TNTP). Agroforest system is one of the land uses that considering ecology, socio-economy aspects in supporting buffer zone TNTP. The objectives of this research were to analyze the structure and composition of agroforest system, as well as to analyze biodiversity vegetation of the agroforestry system in Sungai Sekonyer Village, West Kotawaringin Regency, Central Kalimantan. This research used purposive sampling and vegetation analysis methods. The results showed that the dominant species at sapling level in agroforest system-1 was oil palm (Elaeis guineensis) with IVI 121.54\%, while in agroforest system-2 there was no sapling. The dominant species at pole level both in agroforest systems 1 \& 2 was rubber (H. brasiliensis) with IVI respectively $184.88 \%$ and $187.08 \%$. The dominant species at tree level in agroforest system-1 was sengon (F. moluccana) with $I V I=128.47 \%$, while in agroforestry system-2 was jengkol (A. pauciflorum) with IVI=121.32\%. The diversity indices $\left(H^{\prime}\right)$ and species richness indices (Dmg) for both agroforestry systems were categorized as low. Agroforest management, socio-economic aspect, ecological site, and market are the main factor for species selection that indirectly affecting biodiversity status in agroforest system. Enrichment planting using high economic value species that is suitable to the ecological site is necessary to increase community income as well as biodiversity status.
\end{abstract}

Key words: agroforest, Sungai Sekonyer Village, vegetation biodiversity

\section{PENDAHULUAN}

Hutan memiliki peran penting dalam menyediakan fungsi sosial-ekonomi, juga lingkungan (Sianturi 2001; Mukhamadun et al. 2008; Miura et al. 2015). Hutan mampu menghasilkan produk, baik kayu maupun bukan kayu seperti fungsi hidrologi, wisata, pendidikan, dan bank genetik. Kegiatan pengelolaan hutan seyogyanya mendukung pemanfaatan hasil dan jasa ekosistem hutan dengan mempertimbangkan kelestarian aspek produksi, juga aspek konservasi keanekaragaman hayati. Upaya pengelolaan hutan yang mampu menjamin aspek-aspek tersebut sangat diperlukan, salah satunya adalah melalui sistem agroforestri.

Sistem agroforestri merupakan sistem dan teknologi optimalisasi penggunaan lahan yang mengkombinasikan antara tumbuhan berkayu dengan tanaman pertanian dan atau hewan (ternak) secara terencana, pada satu unit lahan yang sama, dan dilakukan, baik pada waktu yang bersaman ataupun secara bergiliran sehingga terbentuk interaksi antar komponen ekologis dan ekonomis (Lundgren dan Raintree 1982). Agroforestri merupakan salah satu bentuk pengelolaan lahan yang mampu menjaga dan meningkatkan keanekaragaman hayati, namun juga cadangan karbon (Shibu and Sougata 2012; Nair et al. 2010). Agroforestri juga memiliki peran

1 Departemen Silvikultur, Fakultas Kehutanan, IPB Univeristy

* Penulis korespondensi:

E-mail: adistipermatasari@apps.ipb.ac.id penting dalam upaya konservasi keanekaragaman hayati dimana banyak ditemukan spesies-spesies lokal maupun introduksi yang bersifat semi-alami (Atangana et al. 2014). Menurut Lundgren and Raintree (1982), suatu sistem pengelolaan lahan termasuk dalam klasifikasi sistem agroforestri bila memenuhi unsur sebagai berikut: 1) Dua atau lebih spesies tanaman, yang didalamnya terdapat minimal satu spesies tanaman berkayu, 2) memiliki dua atau lebih luaran (outputs), 3) siklus sistem agroforestri selalu lebih dari 1 tahun, 4) agroforestri paling sederhana memiliki struktur, komposisi, dan nilai ekonomi yang lebih tinggi dibandingkan dengan sistem penanaman secara monokultur. De Foresta and Michon (1997) menjelaskan bahwa agroforestri diklasifikasikan menjadi agroforestri sederhana (misalnya, tumpang sari) dan agroforestri kompleks (misalnya, agroforest). Salah satu contoh penerapan sistem agroforest adalah di Desa Sungai Sekonyer, Kabupaten Kotawaringin Barat, Kalimantan Tengah.

Desa Sungai Sekonyer berbatasan langsung dengan Taman Nasional Tanjung Puting, Kalimantan Tengah. Tipe penggunaan lahan di desa tersebut sangat beragam. Sistem perladangan berpindah (swidden agriculture) telah diterapkan sejak dahulu di Kalimantan (Sulistyawati 2001). Sistem tersebut menyebabkan penurunan kesuburan tanah setelah melewati satu atau dua kali masa tanam, sebab pembukaan hutan tersebut dilakukan dengan metode tebang-bakar. Dampak sistem tersebut adalah para petani meninggalkan 
(memberakan) lahannya dan membuka lahan baru (Colfer 1997).

Masyarakat lokal di Desa Sungai Sekonyer telah menerapkan sistem agroforest di daerah penyangga Taman Nasional Tanjung Puting. Agroforest tersebut terbentuk dari pembukaan lahan dengan tebang-bakar. Contoh penerapan agroforest di Desa Sungai Sekonyer adalah agroforest karet. Menurut Michon dan de Foresta (1992), agroforest karet merupakan salah satu bentuk manajemen lahan pertanian ekstensif yang dikelola oleh petani tradisional, memiliki potensi sebagai kawasan yang dapat menampung keanekaragaman hayati dari hutan di sekitarnya. Kawasan tersebut dapat berperan sebagai koridor bagi jenis hewan, terutama jenis yang membutuhkan wilayah sebaran yang luas (Rasnovi 2006).

Berdasarkan latar belakang tersebut, penelitian ini bertujuan untuk: (a) mendeskripsikan tipologi penggunaan lahan di Desa Sungai Sekonyer, Kabupaten Kotawaringin Barat, Kalimantan Tengah, (b) menganalisis struktur, dan komposisi, juga pertumbuhan pada sistem agroforest di Desa Sungai Sekonyer, Kabupaten Kotawaringin Barat, Kalimantan Tengah, (c) menganalisis keanekaragaman hayati vegetasi pada sistem agroforest di Desa Sungai Sekonyer, Kabupaten Kotawaringin Barat, Kalimantan Tengah.

\section{METODE PENELITIAN}

\section{Lokasi dan Waktu Penelitian}

Penelitian ini dilaksanakan di Jerumbun, Desa Sungai Sekonyer, Kecamatan Kumai, Kabupaten Kotawaringin Barat, Provinsi Kalimantan Tengah, pada bulan Juni 2017. Lokasi penelitian disajikan pada Gambar 1.

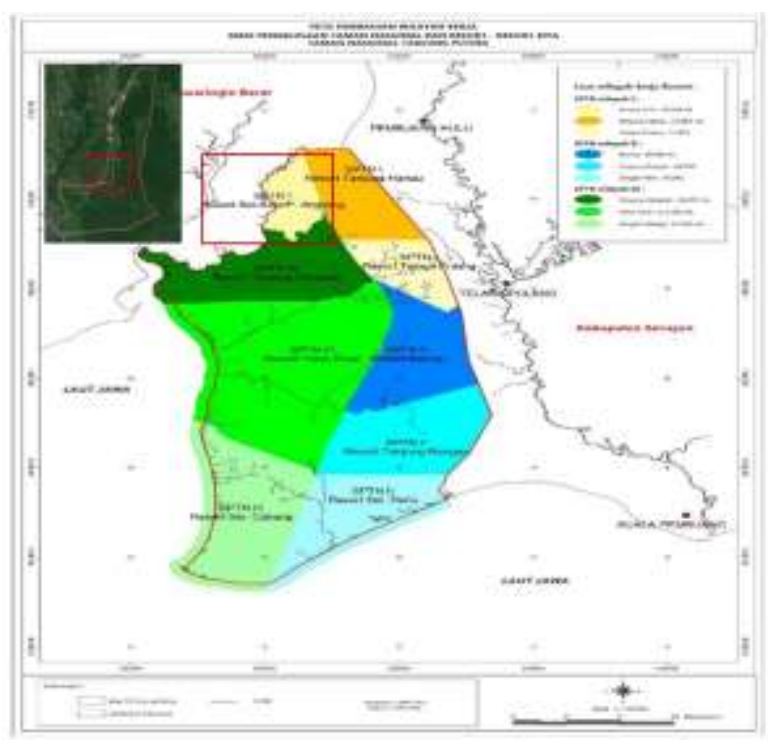

Gambar 1 Lokasi penelitian di Desa Sungai Sekonyer, Kecamatan Kumai, Kabupaten Kotawaringin Barat, Kalimantan Tengah (Sumber: google maps 2019; TNTP 2018)

\section{Alat dan Objek Penelitian}

Alat dan bahan yang digunakan yaitu alat tulis, tally sheet, pita ukur, pita meter, hagameter hypsometer, kompas, GPS (global positioning system) dan kamera. Objek penelitian ini adalah lahan agroforest di Desa Sungai Sekonyer, Kecamatan Kumai, Kabupaten Kotawaringin Barat, Provinsi Kalimantan Tengah.

\section{Prosedur Pengumpulan Data}

Jenis-jenis data yang dikumpulkan dalam kegiatan ini yaitu data primer dan sekunder. Data primer meliputi spesies tanaman, tinggi dan diameter pohon, pola agroforestri, serta hasil wawancara dengan masyarakat lokal. Data sekunder meliputi kondisi umum wilayah (aspek geografis, biofisik, dan keadaan sosial ekonomi). Pemilihan lokasi penelitian dilakukan secara purposive sampling.

\section{Pembangunan Plot}

Pembangunan plot dilakukan di lahan yang menerapkan sistem agroforest campuran. Metode yang digunakan adalah metode purposive sampling. Pengambilan data lapangan dilakukan dengan teknik analisis vegetasi berupa petak berukuran 20 x $20 \mathrm{~m}$ untuk merisalah tiang dan pohon. Sub petak berukuran 2 x 2 m digunakan untuk merisalah semai dan tumbuhan bawah, sedangkan 5 x 5 m digunakan untuk merisalah pancang. Pohon merupakan vegetasi yang memiliki diameter $\geq 20 \mathrm{~cm}$. Tiang merupakan pohon yang memiliki diameter 10 sampai $<20 \quad \mathrm{~cm}$. Pancang merupakan pohon muda dengan tinggi $\geq 1.5 \mathrm{~m}$ dan diameter $<10 \mathrm{~cm}$, sedangkan semai merupakan permudaan pohon dengan tinggi $<1.5 \mathrm{~cm}$. Desain plot menggunakan kombinasi metode jalur dengan metode garis berpetak (Gambar 2).

\section{Analisis Data}

\section{Struktur Tegakan dan Komposisi Tumbuhan pada Sistem Agroforest}

Perhitungan indeks nilai penting (INP) dilakukan untuk mengamati dominansi jenis tumbuhan dalam kelompok di setiap tapak. INP didapatkan dari hasil penjumlahan kerapatan relatif, dominansi relatif, dan frekuensi relatif pada setiap spesies (Mueller-Dombois

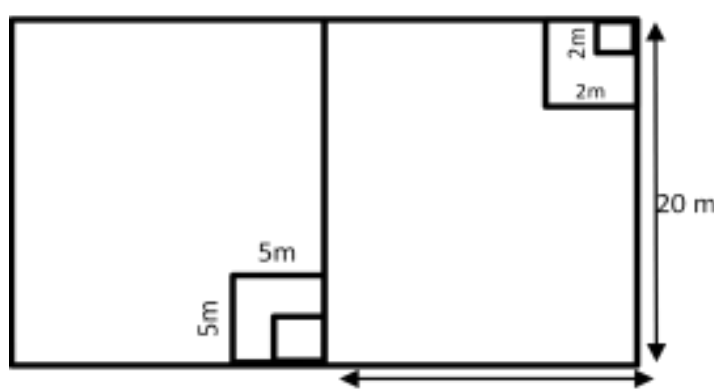

$20 \mathrm{~m}$

Gambar 2 Desain plot penelitian 
dan Ellenberg 1974). Adapun formula yang digunakan untuk menghitung INP menurut Cox (1978) adalah sebagai berikut:

$\begin{array}{ll}\text { Kerapatan }(\mathrm{K}) & =\frac{\text { Jumlah individu tiap jenis }}{\text { Luas plot }} \\ \text { Frekuensi (F) } & =\frac{\text { Jumlah plot penemuan suatu jenis }}{\text { Jumlah seluruh plot }} \\ \text { Dominansi (D) } & =\frac{\text { Luas bidang dasar suatu jenis }}{\text { Luas plot }}\end{array}$

Kerapatan relatif $(\mathrm{KR})=\frac{\text { Kerapatan suatu jenis }}{\text { Kerapatan seluruh jenis }} \times 100 \%$

Frekuensi relatif $(\mathrm{FR})=\frac{\text { Frekuensi suatu jenis }}{\text { Frekuensi seluruh jenis }} \times 100 \%$

Dominansi relatif $(\mathrm{DR})=\frac{\text { Dominansi suatu jenis }}{\text { Dominansi seluruh jenis }} \times 100 \%$

INP tingkat tiang dan pohon: $\mathrm{INP}=\mathrm{KR}+\mathrm{FR}+\mathrm{DR}$

INP tingkat semai dan pancang: $\mathrm{INP}=\mathrm{KR}+\mathrm{FR}$

Identifikasi komposisi spesies tidak hanya dilakukan pada sistem agroforest, namun juga pada tegakan monokultur tanaman kayu, dan kelapa sawit. Lokasi tegakan monokultur tanaman kayu dan lahan kelapa sawit tersebut dipilih berdasarkan kedekatan lokasi di sekitar lokasi penerapan sistem agroforest campuran di Desa Sungai Sekonyer.

\section{Kenakeragaman Hayati Vegetasi pada Sistem Agroforest}

\section{Indeks Keanekaragaman Spesies (H')}

Analisis indeks keanekaragaman spesies (H') dihitung menggunakan rumus keanekaragaman spesies Shannon (Kent \& Paddy 1992) sebagai berikut:

$$
\mathrm{H}^{\prime}=-\Sigma_{\mathrm{i}} \mathrm{Pi} \ln (\mathrm{Pi})
$$

Keterangan: $H^{\prime}=$ Indeks keanekaragaman spesies Shannon

$$
\begin{aligned}
\mathrm{Pi} & =\frac{n i}{N} \\
\mathrm{ni} & =\text { Nilai kerapatan jenis ke-i } \\
\mathrm{N} & =\text { Total kerapatan }
\end{aligned}
$$

Menurut Odum (1996), indeks keanekaragaman $\leq 0.50$ berarti keanekaragamannya rendah, nilai indeks keanekaragaman $\geq 0.50$ sampai $\leq 0.75$ berarti indeks keanekaragamannya sedang, sedangkan $\geq 0.75$ sampai mendekati 1 berarti indeks keanekaragamannya tinggi.

\section{Indeks Kekayaan Spesies (Dmg)}

Indeks kekayaan spesies dihitung menggunakan rumus Margallef (Margalef 1968) yaitu sebagai berikut:

$$
\operatorname{Dmg}=\frac{(\mathrm{S}-1)}{\operatorname{Ln}(\mathrm{N})}
$$

$$
\begin{aligned}
& \text { Keterangan: Dmg }=\text { Indeks kekayaan spesies } \\
& \mathrm{S}=\text { Margallef } \\
& \mathrm{N}=\text { Jumlah spesies yang ditemukan } \\
&
\end{aligned}
$$

Margalef (1968) menjelaskan terdapat 3 kategori indeks kekayaan spesies, yakni rendah ( $D m g<2.5)$, sedang 2.5<Dmg<4.0), dan tinggi (Dmg $>4.0$ ).

\section{Indeks Kemerataan Spesies (E)}

Indeks kemerataan spesies (E) menunjukkan tingkat kemerataan individu per spesies. Nilai E dihitung menggunakan rumus (Pielou 1975 dalam Magurran 1988):

$$
\mathrm{E}=\left(\frac{\mathrm{H} \prime}{\mathrm{LnS}}\right)
$$

Keterangan: $\mathrm{E}=$ Indeks kemerataan spesies

$\mathrm{H}^{\prime}=$ Indeks keanekaragaman spesies

$\mathrm{S}=$ Jumlah seluruh spesies

Menurut Odum (1996), indeks kemerataan spesies secara berturut-turut diklasifikasikan ke dalam kategori merata, cukup merata dan tidak merata jika nilai $\mathrm{E} \geq 0.75$, $0.5 \leq \mathrm{E} \leq 0.75$, dan $\mathrm{E}<0.5$.

\section{Indeks Dominansi (C)}

Indeks dominansi spesies digunakan untuk mengetahui penguasaan suatu spesies pada suatu komunitas. Indeks ini dihitung menggunakan rumus (Simpson 1949 dalam Misra 1980) yaitu:

$$
\mathrm{C}=\sum_{\mathrm{i}=1}^{\mathrm{n}}\left(\frac{\mathrm{ni}}{\mathrm{N}}\right)^{2}
$$

Keterangan: $\mathrm{C}=$ Indeks dominansi spesies

ni $=$ Kerapatan ke-i

$\mathrm{N}=$ Total kerapatan

Indeks dominansi $(\mathrm{C})$ memiliki nilai berkisar antara $0 \leq \mathrm{C} \leq 1$, dimana semakin mendekati nilai 1 maka terdapat spesies yang mendominasi. Sebaliknya, bila nilai $\mathrm{C}$ mendekati nilai 0 , maka tidak ada spesies yang mendominasi pada ekosistem tersebut.

\section{Pembuatan Diagram Profil Tajuk pada Sistem Agroforest}

Pengukuran profil tajuk digunakan untuk membuat diagram profil tajuk pada level pertumbuhan tiang dan pohon. Pengukuran profil tajuk dilakukan pada plot berukuran 20 × $20 \mathrm{~m}$ pada lahan yang menerapkan sistem agroforest campuran. Data yang dibutuhkan adalah:

1. Posisi tiang dan pohon, yakni dengan cara membuat panjang dan lebar jalur (sebagai sumbu X dan Y).

2. Nomor dan spesies yang telah diidentifikasi. Identifikasi spesies tersebut dilakukan pada level pertumbuhan tiang dan pohon yang memiliki diameter $\geq 10 \mathrm{~cm}$.

3. Diameter, tinggi total, tinggi bebas cabang, serta bentuk cabang dan tajuk pada tiang dan pohon.

4. Proyeksi tajuk, yakni dengan mengukur tajuk terpendek dan terpanjang. 


\section{KONDISI UMUM LOKASI}

\section{Aspek Biofisik}

Berdasarkan klasifikasi iklim menurut SchmidtFerguson, kawasan Taman Nasional Tanjung Puting (TNTP) termasuk dalam tipe hujan A (sangat basah). Curah hujan berkisar antara 2000-2500 mm/tahun, dan 51-305 mm/bulan. Curah hujan tertinggi terjadi pada bulan November dan Desember, sedangkan musim kemarau terjadi pada bulan Mei-September. Suhu udara rata-rata di kawasan TNTP antara $25^{\circ} \mathrm{C}-27^{\circ} \mathrm{C}$. Kelembaban nisbi rata-rata bulanan adalah $\pm 84 \%$ (TNTP 2018).

Desa Sungai Sekonyer memiliki 2 jenis tanah, yakni tanah gambut dan tanah mineral. Tutupan lahan TNTP terdiri atas 11 tipe tutupan lahan, yaitu hutan rawa primer, hutan rawa sekunder, hutan mangrove sekunder, rawa, semak/belukar, semak/belukar rawa, tanah terbuka, pemukiman, savana, tambak dan tubuh air (TNTP 2018).

Spesies pohon endemik yang terdapat pada hutan rawa gambut di lokasi penelitian yaitu ramin, jelutung, dan ulin, sedangkan jenis pohon yang ditanam di tanah mineral oleh masyarakat lokal adalah karet, sawit, gaharu dan jenis tanaman komersial lainnya. Kawasan TNTP merupakan habitat alami bagi ratusan spesies pohon dan hewan. Salah satu hewan yang termasuk dalam critical endanger ialah orangutan yang menjadi ikon utama TNTP.

\section{Kependudukan}

Jumlah penduduk di Desa Sungai Sekonyer pada tahun 2017 mencapai 536 orang. Mata pencaharian utama masyarakat desa tersebut adalah sebagai pekerja perkebunan sawit, nelayan, pengelola ekowisata di TNTP dan pengrajin. Masyarakat di Desa Sekonyer juga memiliki kebun di daerah Jerumbun, Desa Sungai Sekonyer yang ditanami dengan beberapa spesies tanaman kehutanan seperti gaharu, karet, dan jengkol. Tingkat konversi lahan menjadi perkebunan sawit yang sangat tinggi menyebabkan sebagian besar masyarakat sekitar tergiur untuk menanam sawit. Komoditi kelapa sawit telah memiliki pasar tersendiri dan pemasaran yang mudah bila dibandingkan dengan komoditi kayu. Selain sebagai petani kelapa sawit dan tanaman kayu, sebagian masyarakat di Desa Sekonyer juga bermata pencaharian sebagai nelayan.

Para nelayan mencari ikan di sekitar Sungai
Sekonyer secara tradisional dengan menggunakan perangkap berupa keramba dan jaring. Peningkatan jumlah wisatawan di TNTP menjadi daya tarik tersendiri bagi masyarakat untuk berpindah pekerjaan menjadi pemandu wisata, jasa penyewaan klotok, dan pengrajin cindera mata bagi wisatawan.

\section{HASIL DAN PEMBAHASAN}

\section{Tipologi Penggunaan Lahan di Desa Sungai Sekonyer}

\section{Sejarah dan Tata Guna Lahan}

Desa Sungai Sekonyer memiliki lahan gambut sekitar 2000 ha yang telah dikonversi menjadi lahan pertanian. Masyarakat mulai mengolah lahan tersebut untuk ditanami padi dengan menggunakan sistem ladang berpindah yang bertujuan untuk mendapatkan hasil pertanian yang lebih tinggi. Pembukaan lahan dengan cara pembakaran menyebabkan penurunan kesuburan tanah sehingga berdampak pada penurunan hasil pertanian. Pembukaan lahan secara besar-besaran dimulai pada tahun 1996 oleh perusahaan sawit di sekitar desa. Tahun 1997 konversi lahan pertanian menjadi perkebunan sawit dilakukan oleh perusahaan PT Bumi Langgeng.

Saat ini pengembangan lahan dengan pola monokultur maupun agroforestri di Desa Sungai Sekonyer dimulai dengan menanam tanaman karet dan gaharu. Beberapa masyarakat kemudian menambahkan beberapa jenis tanaman buah-buahan, seperti cempedak dan nangka untuk meningkatkan pendapatan dan jumlah spesies tanaman. Masyarakat di Desa Sungai Sekonyer, tidak hanya memanfaatkan hasil hutan kayu, namun juga hasil hutan bukan kayu (HHBK) seperti penyadapan getah jelutung dari kawasan TNTP.

Desa Sungai Sekonyer memiliki tipe lahan yang sangat beragam. Hal ini dipengaruhi oleh sejarah penggunaan lahan yakni sistem perladangan berpindah yang sudah ada sejak dahulu seperti yang ditemukan di Sumatera dan Kalimantan (Sulistyawati 2001). Tutupan lahan yang terbentuk dari bekas perladangan berpindah bervariasi mulai dari lahan kosong hingga agroforest. Selain itu, terjadi peningkatan konversi lahan hutan dan pertanian menjadi perkebunan kelapa sawit, baik dilakukan oleh perusahaan maupun masyarakat lokal. Gambaran hasil transek di Jerumbun, Desa Sungai Sekonyer disajikan pada Gambar 3.

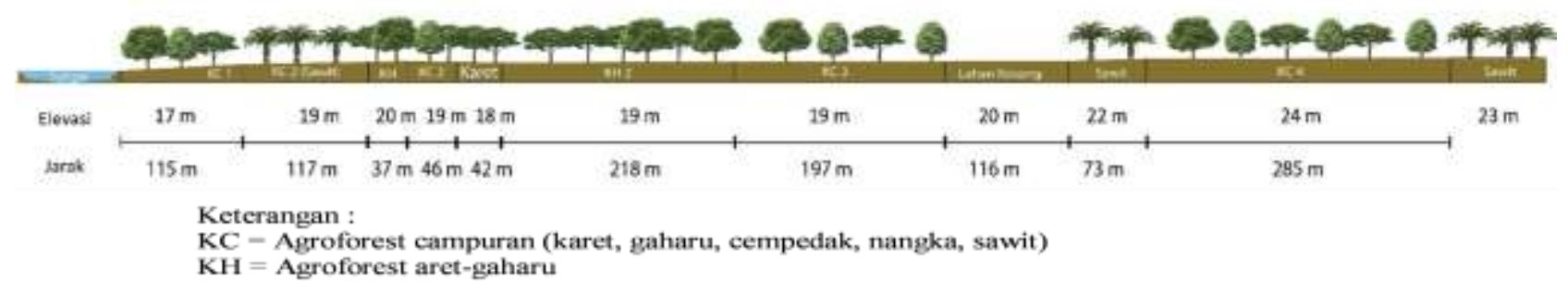

Gambar 3 Tansek dari Sungai Sekonyer sampai perkebunan kelapa sawit di Desa Sekonyer (Skala 1:1000) 
Berdasarkan pengamatan lapang secara langsung ditemukan 5 jenis tipe penggunaan lahan, yaitu agroforest campuran, agroforest karet dan gaharu, kebun karet monokultur, kebun gaharu monokultur, dan kebun sawit. Agroforest campuran terdiri atas pohon karet yang dipadukan dengan cempedak, jengkol, kelapa sawit dan pohon buah lainnya. Kelapa sawit pada agroforest campuran ditanam secara acak di sela-sela larikan tanaman kehutanan. Agroforest karet dan gaharu ditanam dengan jarak teratur dan berseling. Komposisi jenis penyusun kebun masyarakat di Desa Sungai Sekonyer disajikan pada Tabel 1.

\section{Agroforest Campuran sebagai Sistem Agroforestri Kompleks}

Sistem agroforest dan hutan memiliki kesamaan, yakni adanya suatu proses alami dan bertahap yang terjadi selama pembentukan agroforest, secara spesifik dalam penelitian ini adalah pada agroforest campuran. Proses alami tersebut akan terus berjalan hingga mencapai tahapan tertentu. Spesies utama pada sistem agroforest campuran di Desa Sungai Sekonyer adalah karet (H. brasiliensis). Menurut Beukema et al. (2007), selama kurun waktu 8-10 tahun karet mampu tumbuh besar bersama jenis lainnya yang tersedia maupun yang telah menyebar dari hutan terdekat. Komponen agroforest tersebut membentuk struktur yang menyerupai hutan sekunder. Menurut Joshi et al. (2002), selain berdasarkan penampakan visual, agroforest karet juga memiliki struktur vegetasi yang berlapis (multilayers) dan siklus unsur hara yang hampir tertutup seperti di hutan alam. Proses penyadapan karet dapat berjalan sampai karet tersebut berumur 60 tahun dan selama itu pula lahan akan mengalami proses perubahan secara alami untuk mencapai suatu komunitas yang stabil atau klimaks, atau yang disebut dengan suksesi (Barbour et al. 1999).

\section{Struktur Tegakan dan Komposisi Spesies pada Sistem Agroforest Campuran}

Analisis vegetasi pada kedua agroforest campuran dilakukan pada tingkat pertumbuhan pancang, tiang dan pohon. Hal ini disebabkan tidak ditemukan semai dan tumbuhan bawah di kedua lokasi tersebut.

Spesies yang ditemukan pada agroforest campuran-1 sebanyak 8 spesies, sedangkan pada agroforest campuran-2 sebanyak 4 spesies. Hasil analisis vegetasi menunjukkan bahwa pada agroforest campuran-1 ditemukan tingkat pertumbuhan pancang, tiang dan pohon, sedangkan pada agroforest campuran-2 tidak ditemukan tingkat pertumbuhan pancang. Hal ini menunjukkan regenerasi spesies pada agroforest kebun campuran-2 tidak berjalan normal. Enrichment planting perlu dilakukan pada lokasi agroforest campuran-2. Spesies yang direkomendasikan untuk ditanam adalah spesies yang memiliki nilai ekonomi tinggi, dan cocok dengan kesesuaian habitat. Menurut Hartoyo et al. (2018), enrichment planting dengan menggunakan spesies yang bernilai ekonomi tinggi dan sesuai dengan habitat pada sistem agroforestri, mampu meningkatkan distribusi spesies dan heterogenitas spesies (keanekaragaman hayati vegetasi).

Tingkat pertumbuhan pancang di agroforest campuran-1 disusun oleh 3 jenis tanaman yaitu sawit (Elaeis guineensis), rambutan (Nephelium lappaceum) dan cempedak (Artocarpus integer). Spesies yang mendominasi pada tingkat pancang tersebut adalah sawit (E. guineensis) dengan nilai INP sebesar $121.54 \%$ (Tabel 2).

Berdasarkan perhitungan INP, spesies yang mendominasi (spesies utama) pada tingkat tiang di kedua lokasi agroforest campuran adalah karet $(H$. brasiliensis) dengan nilai INP sebesar $184.88 \%$ pada agroforest campuran-1 dan $187.08 \%$ pada agroforest campuran-2 seperti tertera pada Tabel 3. Pada awal penanaman, karet tersebut ditanam dengan pola monokultur, dan secara bertahap ditanam bersama dengan tanaman pendamping lainnya.

Tabel 1 Komposisi jenis yang ditemukan pada beberapa tipe penggunaan lahan di Desa Sungai Sekonyer

\begin{tabular}{|c|c|c|c|c|c|}
\hline \multirow{2}{*}{ No. } & \multirow{2}{*}{ Pola Tanam } & \multirow{2}{*}{ Kombinasi } & \multicolumn{3}{|c|}{ Jenis Tanaman } \\
\hline & & & Kayu & Perkebunan & Buah \\
\hline 1 & $\begin{array}{l}\text { Agroforest } \\
\text { campuran-1 }\end{array}$ & $\begin{array}{l}\text { Kayu }+ \\
\text { perkebunan }+ \\
\text { buah }\end{array}$ & $\begin{array}{l}\text { Karet (Hevea brasiliensis), } \\
\text { Sengon (Falcataria } \\
\text { moluccana), Gaharu } \\
\text { (Aquilaria malaccensis) }\end{array}$ & $\begin{array}{l}\text { Sawit (Elaeis } \\
\text { guineensis) }\end{array}$ & $\begin{array}{l}\text { Asam (Tamarindus indica), } \\
\text { Rambutan (Nephelium lappaceum), } \\
\text { Jengkol (Archidendron pauciflorum) }\end{array}$ \\
\hline 2 & $\begin{array}{l}\text { Agroforest } \\
\text { campuran-2 }\end{array}$ & Kayu + buah & Karet (Hevea brasiliensis) & - & $\begin{array}{l}\text { Cempedak (Artocarpus integer), } \\
\text { Mangga (Mangifera indica), Jengkol } \\
\text { (Archidendron pauciflorum) }\end{array}$ \\
\hline 3 & $\begin{array}{l}\text { Agroforest } \\
\text { Karet-Gaharu }\end{array}$ & Kayu & $\begin{array}{l}\text { Karet (Hevea brasiliensis), } \\
\text { Gaharu (Aquilaria } \\
\text { malaccensis) }\end{array}$ & - & - \\
\hline 4 & Monokultur & Kayu & Karet (Hevea brasiliensis) & - & - \\
\hline 5 & Monokultur & Kayu & $\begin{array}{l}\text { Gaharu (Aquilaria } \\
\text { malaccensis) }\end{array}$ & - & - \\
\hline 6 & Monokultur & Perkebunan & - & $\begin{array}{l}\text { Sawit (Elaeis } \\
\text { guineensis) }\end{array}$ & - \\
\hline
\end{tabular}


Berdasarkan Tabel 4, nilai INP pada tingkat pertumbuhan pohon pada agroforest campuran-1 didominasi oleh sengon (Falcataria moluccana) dengan nilai INP sebesar $128.47 \%$. Spesies yang mendominasi pada agroforest campuran-2 adalah jengkol (Archidendron pauciflorum) dengan nilai INP sebesar $121.32 \%$.

Sengon ( $F$. moluccana) dan jengkol (A. pauciflorum) merupakan fast growing species yang banyak ditanam oleh masyarakat Desa Sungai Sekonyer. Jengkol (A. pauciflorum) termasuk dalam multipurposes tree species, yang tidak hanya dapat dimanfaatkan kayunya namun juga buahnya. Penanaman spesies yang memproduksi hasil hutan bukan kayu (misalnya buah-buahan, resin, getah, dan sebagainya) yang dapat dimanfaatkan oleh masyarakat, dapat menjadi salah satu upaya konservasi hutan. Hal ini disebabkan masyarakat lokal tidak akan menebang kayu, selama mereka memperoleh manfaat secara ekonomi dari hasi hutan bukan kayu tersebut.

Berdasarkan analisis aspek ekonomi yang dilakukan pada tahun 2017, jenis tanaman yang mampu memberikan pemasukan bagi petani yaitu jengkol. Jenis tanaman karet, gaharu dan sengon, serta tanaman buah lainnya belum menghasilkan pendapatan dikarenakan

Tabel 2 Hasil analisis vegetasi tingkat pancang pada sistem agroforest campuran-1

\begin{tabular}{clccc}
\hline No. & Spesies & $\begin{array}{c}\mathrm{KR} \\
(\%)\end{array}$ & $\begin{array}{l}\text { FR } \\
(\%)\end{array}$ & $\begin{array}{c}\text { INP } \\
(\%)\end{array}$ \\
\cline { 2 - 3 } 1 & $\begin{array}{l}\text { Sawit (Elaeis } \\
\text { guineensis) }\end{array}$ & 61.54 & 60.00 & 121.54 \\
2 & $\begin{array}{l}\text { Rambutan (Nephelium } \\
\text { lappaceum) }\end{array}$ & 30.77 & 20.00 & 50.77 \\
3 & $\begin{array}{l}\text { Cempedak (Artocarpus } \\
\text { integer) }\end{array}$ & 7.69 & 20.00 & 27.69 \\
\hline
\end{tabular}

belum masuk tahun panen dan baru ditanam oleh masyarakat. Jenis buah-buahan seperti asam, mangga, rambutan dan cempedak tergolong jenis yang dimanfaatkan oleh masyarakat untuk konsumsi pribadi. Pemasaran hasil panen jengkol dilakukan saat panen yaitu satu tahun sekali dengan rata-rata produktivitas $100 \mathrm{~kg} /$ pohon/tahun atau sama dengan 400 $\mathrm{kg} / \mathrm{kebun} / \mathrm{tahun}$ dengan pendapatan yang diperoleh sebesar Rp 4000 000/tahun. Sistem pemasaran jengkol tergolong tradisional, yaitu pengepul mendatangi masyarakat petani jengkol untuk membeli secara langsung.

Karet ditanam oleh masyarakat lebih dahulu daripada sengon dan jengkol, namun pertumbuhan kedua spesies tersebut lebih cepat sehingga dapat mendominasi tingkat pohon. Hal tersebut menunjukkan bahwa sengon dan jengkol memiliki tingkat adaptasi yang tinggi. Menurut Haryanto et al. (2015), jenis yang memiliki nilai INP tertinggi mampu bersaing pada suatu daerah tertentu dan mempunyai toleransi yang tinggi dibandingkan jenis lainnya.

\section{Keanekaragaman Hayati Vegetasi pada Sistem Agroforest Campuran}

Hasil perhitungan indeks keanekaragaman spesies Shannon-Wiener (H'), menunjukkan bahwa keanekaragaman jenis penyusun agroforest campuran 1 dan 2 berkisar antara 0.40-0.48 (Tabel 5). Berdasarkan kategori Odum (1996), keanekaragaman spesies di kedua lokasi tersebut termasuk dalam kelas rendah. Hasil tersebut didukung oleh hasil penelitian Sumarhani dan Kalima (2015) bahwa keanekaragaman jenis pohon penyusun agroforestri tembawang di Desa Sei Dangin, Kecamatan Noyan, Kabupaten Sanggau berkisar antara 0.14-0.76. Rendahnya indeks keanekaragaman spesies pohon pada sistem tembawang disebabkan oleh aktivitas

Tabel 3 Hasil analisis vegetasi tingkat tiang pada sistem agroforest campuran-1 dan agroforest campuran-2

\begin{tabular}{llccccccccc}
\hline & \multirow{2}{*}{ No. Spesies } & \multicolumn{4}{c}{ Agroforest campuran-1 } & \multicolumn{4}{c}{ Agroforest campuran-2 } \\
\cline { 3 - 10 } & & KR & FR & DR & INP & KR & FR & DR & INP \\
$(\%)$ & $(\%)$ & $(\%)$ & $(\%)$ & $(\%)$ & $(\%)$ & $(\%)$ & $(\%)$ \\
\hline 1 & Asam (Tamarindus indica) & 1.37 & 12.50 & 0.98 & 14.85 & - & - & - & - \\
2 & Gaharu (Aquilaria malaccensis) & 2.74 & 12.50 & 0.94 & 16.18 & - & - & - & - \\
3 & Karet (Hevea brasiliensis) & 71.23 & 37.50 & 76.15 & 184.88 & 77,42 & 33,33 & 76,32 & 187,08 \\
4 & Rambutan (Nephelium lappaceum) & 4.11 & 12.50 & 1.30 & 17.91 & - & - & - & - \\
5 & Sengon (Falcaratia moluccana) & 20.55 & 25.00 & 20.63 & 66,18 & - & - & - & - \\
6 & Cempedak (Artocarpus integer) & - & - & - & - & 12,90 & 33,33 & 14,11 & 60,34 \\
7 & Mangga (Mangifera indica) & - & - & - & - & 9,68 & 33,33 & 9,57 & 52,58 \\
\hline
\end{tabular}

Tabel 4 Hasil analisis vegetasi tingkat pohon pada sistem agroforest campuran-1 dan agroforest campuran-2

\begin{tabular}{llccccccccc}
\hline & \multirow{2}{*}{ Spesies } & \multicolumn{4}{c}{ Agroforest campuran-1 } & \multicolumn{4}{c}{ Agroforest campuran-2 } \\
\cline { 3 - 10 } No. & & KR & FR & DR & INP & KR & FR & DR & INP \\
& & $(\%)$ & $(\%)$ & $(\%)$ & $(\%)$ & $(\%)$ & $(\%)$ & $(\%)$ & $(\%)$ \\
\hline 1 & Karet (Hevea brasiliensis) & 33.33 & 40.00 & 27.52 & 100.85 & 33.33 & 33.33 & 23.27 & 89.94 \\
2 & Sengon (Falcataria moluccana) & 50.00 & 40.00 & 38.47 & 128.47 & & & & \\
3 & Jengkol (Archidendron pauciflorum) & 16.67 & 20.00 & 34.01 & 70.67 & 33.33 & 33.33 & 54.65 & 121,32 \\
4 & Cempedak (Artocarpus integer) & & & & & 33.33 & 33.33 & 22.08 & 88.74 \\
\hline
\end{tabular}


manusia yang merugikan, baik sebelum maupun sesudah terbentuknya sistem agroforestri tembawang. Peran manusia dalam pengelolaan sistem agroforestri tembawang cenderung akan mempertahankan spesiesspesies yang bermanfaat dari segi nilai ekonomi dan menghilangkan spesies yang dianggap tidak komersial. Menurut Hartoyo et al. (2018), cara pengelolaan agroforest, kesesuaian lahan, nilai ekonomi, dan pasar merupakan faktor utama pemilihan spesies yang secara tidak langsung mempengaruhi keanekaragaman spesies pada sistem agroforest di Kalimantan Timur. Selain itu nilai indeks keanekaragaman spesies yang tergolong rendah di kedua sistem agroforest campuran disebabkan oleh umur sistem yang relatif muda, dan penanaman karet secara monokultur sekitar tahun 2012.

Indeks kekayaan spesies (Dmg) di kedua lokasi tersebut tergolong dalam kategori rendah, sedangkan indeks kemerataan (E) tergolong dalam kategori tidak merata. Dominansi hanya ditemukan pada sistem agroforest campuran-1 yakni pada tingkat pertumbuhan tiang. Spesies yang mendominasi adalah karet $(H$. brasiliensis).

\section{Diagram Profil Tajuk}

Diagram profil tajuk pada plot contoh agroforest campuran 1 dan 2 menunjukkan bahwa sebagian besar tiang dan pohon terdapat pada kelas tinggi 10-20 m (stratum C). Jenis yang mendominasi startum $\mathrm{C}$ yaitu karet (Hevea brasiliensis). Spesies yang mendominasi pada kelas tinggi 1-4 m (stratum D) adalah kelapa sawit (Elaeis guineensis). Pada kelas tinggi 20-30 m (Strata B) dan kelas tinggi $>30 \mathrm{~m}$ (stratum A) tidak ditemukan tiang maupun pohon yang tumbuh (Gambar 4 dan 5). Hal tersebut menunjukkan bahwa untuk mencapai stratum A dan B sangat sulit, terlebih umur tanaman masih relatif muda kurang dari 6 tahun. Menurut
Kusmana dan Susanti (2015) sulitnya pohon mencapai stratum A dikarenakan untuk mencapai stratum A dan B membutuhkan waktu yang lama dan persaingan yang tinggi, baik dari segi nutrisi, air tanah, maupun cahaya.

\section{SIMPULAN DAN SARAN}

\section{Simpulan}

Total individul per ha pada sistem agroforest campuran-1 dan agroforest campuran-2 secara berturutturut adalah 617 individu/ha dan 825 individu/ha. Spesies yang mendominasi tingkat pancang pada sistem agroforest campuran-1 adalah sawit (E. guineensis) dengan nilai $\mathrm{INP}=121.54 \%$, sedangkan pada sistem agroforest campuran-2 tidak ditemukan pancang. Spesies yang mendominasi tingkat tiang pada kedua sistem agroforest campuran adalah karet $(H$. brasiliensis) $\quad(\mathrm{INP}=184.88 \%$ dan $187.08 \%)$. Spesies yang mendominasi tingkat pohon pada sistem agroforest campuran-1 adalah sengon ( $F$. moluccana) dengan nilai INP $128.47 \%$, sedangkan pada sistem agroforest campuran-2 didominasi oleh jengkol (A. pauciflorum) dengan nilai INP $=121.32 \%$.

Indeks keanekaragaman spesies (H') dan kekayaan spesies (Dmg) pada kedua lokasi tersebut tergolong dalam kategori rendah, sedangkan indeks kemerataan (E) tergolong dalam kategori tidak merata. Strata tajuk tertinggi di kedua agroforest campuran tersebut tergolong dalam startum C (10-20 m). Cara pengelolaan agroforest, kesesuaian lahan, nilai ekonomi, dan pasar merupakan faktor utama pemilihan spesies yang secara tidak langsung mempengaruhi keanekaragaman spesies pada sistem agroforest.

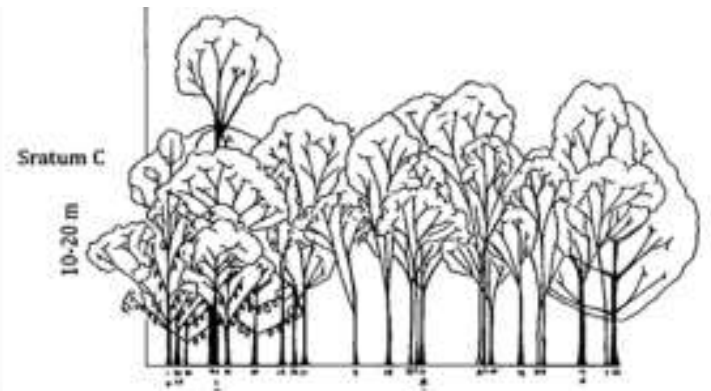

Gambar 5 Diagram profil tajuk agroforest campuran-2

Tabel 5 Keanekaragaman spesies penyusun kebun karet campuran

\begin{tabular}{llllll}
\hline \multicolumn{1}{c}{ Tipe } & $\begin{array}{c}\text { Tingkat } \\
\text { Pertumbuhan }\end{array}$ & H' & Dmg & E & C \\
\hline Agroforest & Pohon & 0.46 & 1.12 & 0.42 & 0.39 \\
campuran-1 & Tiang & 0.48 & 0.93 & 0.30 & 0.55 \\
& Pancang & 0.40 & 0.78 & 0.37 & 0.48 \\
\hline Agroforest & Pohon & 0.47 & 1.82 & 0.43 & 0.33 \\
campuran-2 & Tiang & 0.40 & 0.58 & 0.36 & 0.63 \\
\hline
\end{tabular}

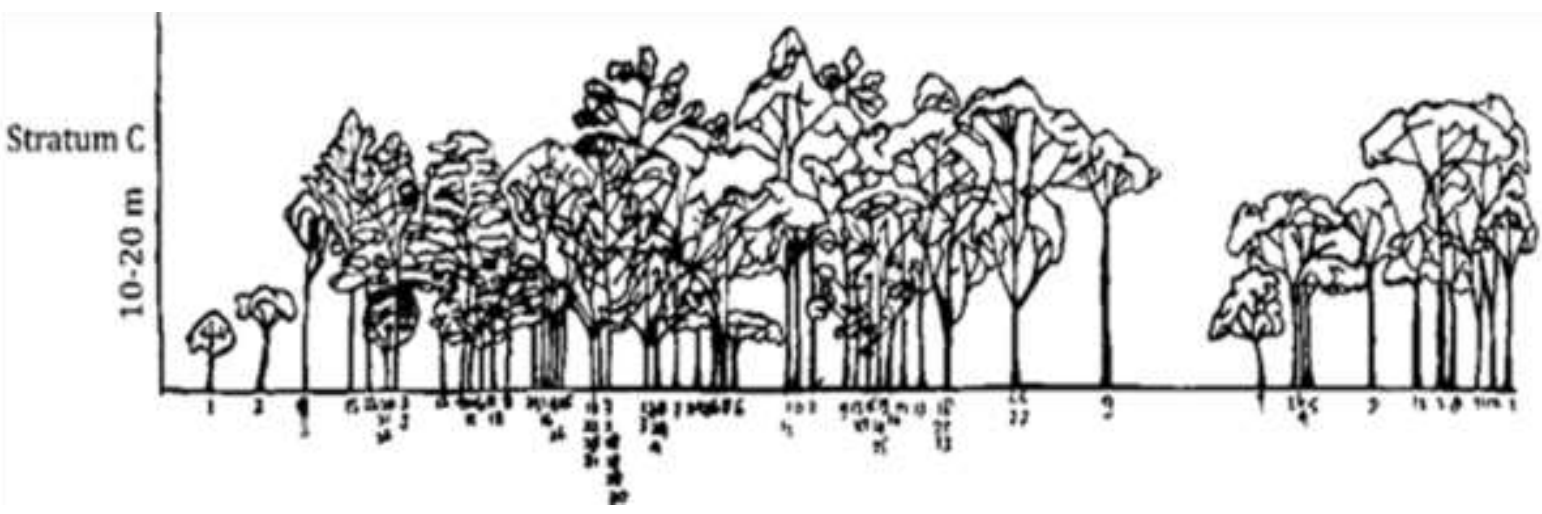

Gambar 4 Diagram profil tajuk agroforest campuran-1 


\section{Saran}

Enrichment planting dengan menggunakan spesies yang bernilai ekonomi tinggi dan sesuai dengan habitat di kedua lokasi penelitian sangat diperlukan untuk meningkatkan pendapatan masyarakat dan keanekaragaman hayati vegetasi. Pemanfaatan lahan dibawah tegakan karet dan diperlukan untuk menambah pendapatan masyarakat misalnya penanaman padi ladang (padi gogo) yang merupakan tanaman yang pernah dibudidayakan sebelum masuknya jenis kelapa sawit, juga penanaman jagung. Setelah tajuk karet mulai rapat, masyarakat perlu melakukan pemangkasan tajuk secara berkala agar tanaman sela/pendamping mendapatkan kecukupan sinar matahari.

\section{DAFTAR PUSTAKA}

Atangana A, Khas D, Chang S, Degrande A. 2014. Tropical Agroforestry. America Latin (US): Springer.

Barbour GM, Burk JK, Pitts WD, William FS. 1999. Terrestrial Plant Ecology. Third Edition. Addisson Wesley Longman, Inc. California

Beukema H, Danielsen F, Vincent G, Hardiwinoto S van Andel J. 2007. Plant and bird diversity in rubber agroforests in the lowlands of Sumatra, Indonesia. Agroforestry Systems. 70:217-242.

Colfer CJP. 1997. Beyond Slash and Burn, Building on Indigenous Management of Borneo's Tropical Rain Forest. New York (US): The New York Botanical Garden.

Cox GW. 1978. Laboratory Manual of General Ecology. USA :WM.C. Brown Company Publisher.

De Foresta H, Michon G. 1997. The agroforest alternative to Imperata grasslands: when smallholder agriculture and forestry reach sustainability. Agroforestry Systems. 36:105-120.

Hartoyo APP, Supriyanto, Siregar IZ, Theilade I, Prasetyo LB. 2018. Agroforest diversity and ethnobotanical aspects in two villages of Berau, East Kalimantan, Indonesia. Biodiversitas Journal. 19 (2): 2018. DOI: 10.13057/biodiv/d190205

Haryanto DA, Astiani D, Manurung TF. 2015. Analisa vegetasi tegakan hutan di areal hutan kota Gunung Sari Kota Singkawang. Jurnal Hutan Lestari. 3 (2): $217-226$.

Joshi L, Wibawa G, Vincent G, Boutin D, Akiefnawati R, Manurung R, Noordwijk M, Williams S. 2002. Jungle Rubber: Traditional Agroforestry System Underpressure. Bogor (ID): Word Agroforestry Centre (ICRAF).

Kent M, Paddy C. 1992. Vegetation Description And Analysis A Practical Approach. London: Belhaven Press.

Kusmana C, Susanti S. 2015. Komposisi dan struktur tegakan hutan alam di Hutan Pendidikan Gunung Walat, Sukabumi. Jurnal Silvikultur Tropika. 5(3): $210-217$.

Lundgren BO, Raintree JB. 1982. Sustained Agroforestry. In: Nestel B, editor. Agricultural
Research for Development: Potentials and Challenges in Asia. Netherland: ISNAR, The Hague. pp 37-49.

Magurran AE. 1988. Measuring Biological Diversity. United Kingdom (GB): TJ International, Padstow, Corbwall.

Margalef R. 1968. Perspective in Ecological Theory. Chicago (US): University of Chicago Press. pp 112 .

Michon G, de Foresta H. 1992. Complex Agroforestry Systems and Conservation of Biological Diversity Agroforestry in Indonesia: a link between two worlds. The Malayan Nature Journal Golden Jubilee issue. 457-473.

Misra KC. 1980. Manual of Plant Ecology Second Edition. New Delhi (IN): Oxford and IBH Publishing Co.

Miura S, Amacher M, Hofer T, San Miguel S, Ernawati, Thackway R. 2015. Protective functions and ecosystem services of global forests in the past quarter-century. For. Ecol. Manage. 352: 35-46.

Mueller-Dombois D, Ellenberg H. 1974. Aims and Methods of Vegetation Ecology. Canada (US): J Wiley.

Mukhamadun, Efrizal T, \& Tarumun S. 2008. Valuasi ekonomi Hutan Ulayat Buluhcina Desa Buluhcina Kecamatan Siak Hulu Kabupaten Kampar. Ilmu Lingkungan. 3 (2): 55 - 73.

Nair PKR, Vimala D. Nair, B. Mohan Kumar, Julia MS. 2010. Carbon Sequestration in Agroforestry Systems. Advances in Agronomy. 108.

Odum EP. 1996. Dasar-dasar Ekologi. Ed ketiga. Yogyakarta (ID): Universitas Gajah Mada Press.

Rasnovi S. 2006. Ekologi Regenerasi Tumbuhan Berkayu pada Sistem Agroforest Karet [disertasi]. Bogor (ID): Sekolah Pasca Sarjana, Institut Pertanian Bogor.

Rizkiyah N, Dewantara I, Herawatiningsih R. 2013. Keanekaragaman vegetasi tegakan penyusun hutan tembawang Dusun Semoncol Kabupaten Sanggau. Jurnal Hutan Lestari. 1 (3): 367-373.

Shibu J, Sougata B. 2012. Agroforestry for biomass production and carbon sequestration: an overview. Agroforest Syst. 86:105-111.

Shukla RS, Chandel PS. 1982. Plant Ecology. New Delhi: S. Chand \& Company, Ltd. Ram Nagar.

Sianturi A. 2001. Analisis penerimaan sumberdaya hutan. Jurnal Sosial Ekonomi. 2 (1): 1-14.

Sulistyawati E. 2001. An Agent-Based Simulation of Land-use in Swidden Agricultural Landscape of The Kantu' in Kalimantan, Indonesia. A thesis for the degree of Doctor of Philosophy of the Australia National University.

Sumarhani dan Kalima T. 2015. Struktur dan komposisi vegetasi agroforstri tembawang di Kabupaten Sanggau, Kalimantan Barat. Pros Sem Nas Masy Biodiv Indon 1(5): 1099-1104.

[TNTP] Taman Nasional tanjung Puting. 2018. Biofisik kawasan [internet]. Tersedia pada https://tntanjungputing.org/keadaan-umumwilayah/. Diakses pada 1 Agustus 2019. 